\title{
Social mobility and health related behaviours in young people
}

\author{
Sakari Karvonen, Arja H Rimpelä, Matti K Rimpelä
}

\begin{abstract}
Study objective-To assess the influences related to social mobility, particularly health related behaviours, as one potential explanation for the social class variation in health among adults.
\end{abstract}

Design-The study is based on questionnaire data from the Adolescent Health and Lifestyle Surveys of 1985, 1987, and 1989.

Setting-The whole of Finland.

Participants-A representative sample of 8355 adolescents. The response rate was $79 \%$.

Measurement and main results-The relation between social mobility and health related behaviours among 16 and 18 year old young people was studied.The measure of social mobility was based on a combination of the social class of origin and achieved social position measured by the present educational status, educational attainment, and labour market position. Three mobility groups were constructed: the downwardly mobile, the upwardly mobile and the stable. Health related behaviours in an upwardly or downwardly mobile group were compared with a stable group from the same social class of origin by calculating relative risks (RR). RRs were assessed by calculating age and sex adjusted rate ratios approximating a Mantel-Haenszel estimate. In logistic regression analyses the independent effects of the social class of origin and the achieved social position were investigated.

Department of Public Health, University of Helsinki, Finland

S Karvonen

Tampere School of Public Health, University of Tampere, Finland

A H Rimpelä

National Research and Development Centre for Welfare and Health, Finland M K Rimpelä

Correspondence to: Sakari Karvonen, Department of Public Health, University of Helsinki, PO Box 41

(Mannerheimintie 172), FIN-00014, Helsinki, Finland.

Accepted for publication 13 July 1998
In the course of the debate about the determinants of social class variation in health, social mobility and factors associated with it have been suggested to play an important part in creating this variation. ${ }^{1-4}$ The extent to which social mobility attributable to health can directly contribute to the overall patterning of health by social class is, however, apparently rather small. Instead, social mobility may influence indirectly as in this case both adult health and social status are determined by one and the same factor that is associated with mobility. This is also referred to as indirect health selection. ${ }^{5-8}$

Given that the social hierarchy is modified through social mobility, it is interesting that the role of social mobility itself as a determinant of health has been poorly conceptualised. This can be seen in the way that the results concerning the relation between height and social mobility are interpreted. Height has been suggested to have an independent relation to health as well as to social mobility so that taller persons are more likely to be upwardly mobile than are short people. ${ }^{9-11}$ Yet height itself can be considered as a measure of health.

The relevance of social mobility has mostly been analysed in connection with height. However, the experience of social mobility may influence health in many ways ranging from direct effects, such as morbidity created through psychological stress resulting from status inconsistency, ${ }^{12}$ to more indirect effects operating through such cultural factors as health related behaviours. ${ }^{13}$ As health related behaviours are associated with health outcomes, they could explain health variation between social classes. Indeed, Power et $a l^{14} 15$ found smoking habits at 16 years to explain more of the variation between social classes in self rated health at 23 years than health status at 16 years.

Based on their review of the literature concerning social selection, Blane et $a l^{8}$ suggest that health related behaviours could make a major contribution to class differentials in adult health as behaviours may influence both the direction of social mobility and future health status. According to the authors, adolescence and the point of entry to the labour market are crucial life phases, as behaviours adopted during and before labour market entry may, through educational qualifications, influence the chances and the direction of social mobility. Also, this age is characterised by a lot of mobility because the unqualified adolescents often begin their occupational career from short term, low status positions. ${ }^{16}$ 
Table 1 Dates of birth of the samples, number of respondents, and response rates by study year

\begin{tabular}{|c|c|c|c|c|c|}
\hline \multirow[b]{2}{*}{ Study year } & \multirow[b]{2}{*}{ Dates of birth of the samples } & \multicolumn{2}{|c|}{ Number } & \multicolumn{2}{|c|}{ Response rate (\%) } \\
\hline & & Boys & Girls & Boys & Girls \\
\hline 1985 & 14-19 Jul 1966 & 854 & 960 & 72 & 85 \\
\hline 1987 & 14-31 Jul 1968 and 1970 & 2317 & 2685 & 73 & 86 \\
\hline 1989 & 28-30 Jun and 1-3 Aug, 1970 and 1972 & 724 & 815 & 70 & 84 \\
\hline Total & & 3895 & 4460 & 72 & 86 \\
\hline
\end{tabular}

Social mobility is associated with the social class of origin of the young people and their current, achieved social position, which can be measured by their educational level and achievements. As the social class hiearchy is based on educational qualifications, they may be used to anticipate future social position. Recently Lynch et $a l^{17}$ showed that among Finnish men aged 42 to 60 education strongly associates with social position. Practically all $(98 \%)$ those with a high school degree were employed in white collar occupations, whereas primary education had predominantly (58\%) led to blue collar occupations. Even those with poor social background of origin who had managed to complete at least high school had a high chance of upward social mobility. In a younger Finnish cohort health related behaviours were found to anticipate educational status at adult age. ${ }^{18}$ Particularly smoking at young age predicted low adult educational status. Neither of the studies, however, considered the role of social mobility as a potential determinant of health related behaviours.

The selective processes that are related directly to social mobility probably produce variation in health to a small degree. According to our view, however, it is more probable, that this variation relates to the more indirect selective influences. We propose a model where social mobility experienced at young age is associated with health related behaviour, which, in turn, would result in differences between social classes in adult health. The poorer health status of lower social classes would result - at least partly-from the fact that people moving down in the social hierarchy tend to adopt behaviour detrimental to their health. Respectively, upward mobility would associate with behaviour that is more favourable to health. Indeed, Burrows and Nettleton ${ }^{19}$ found that smoking and drinking among middle class men were related to the experience of social mobility so that the upwardly mobile men were less likely than the stable ones to have adopted these behaviours. According to Glendinning et $a l^{20}$ smoking was among young people related to social mobility in Scotland. Apart from smoking, the relation between social mobility and health related behaviour among young people has not been studied.

There are three types of influences that can be expected to contribute to the health related behaviour consequences of social mobility. Firstly, persons moving in the social hierarchy may basically adapt to the behaviours of the social class they are about to enter. Secondly, the person could also stick to the behaviour patterns that are prevalent in the social class of their origin. Thirdly, the fact that they are experiencing mobility may itself also contribute to health related behaviours. To cope with the stress that results from status inconsistency a person could, for example, adopt health compromising behaviours, which, then, would produce this movement effect.

The purpose of our study is to analyse whether social mobility is related to the adoption of health related behaviours among young people. We compare those, who are likely to remain in a social position that is equivalent to their parents' position (the stable ones), to those with a similar background, who are likely to move up or down (the mobiles) in the social hierarchy. In this way, we aim, firstly, to describe the overall consequences of social mobility from the point of view of health related behaviours. Our second aim is to analyse the factors that produce particular mobility outcomes in health related behaviours. However, the social class of origin as well as the influences that relate to the achieved social position have to be taken into account, before the contribution of the movement effect can be estimated. This is done by means of multivariate analyses where the independent effects of the social class of origin and the achieved social position are controlled.

\section{Methods}

This study is part of the Adolescent Health and Lifestyle Survey where a 12 page questionnaire concerning health, health related behaviour, and socioeconomic background factors has been sent to a nationwide representative sample of 12, 14, 16, and 18 year old Finns every second year since $1977 .^{21}$ The sample was obtained from the Population Register Centre and each year it included all Finns born on particular days of July (in 1989 also some days in June and August) thus standardising the age structure (table 1).

Survey data from the 1985, 1987, and 1989 were combined to give us a number of respondents large enough for divisions into the categories of social mobility. Merged data from three different surveys could be used as data collection methods, questions, timing of inquiry, and sample were kept as identical as possible in each survey.

Only the 16 and 18 year olds were selected for the present analyses. At the age of 12 and 14 the entire age group is in Finland within the comprehensive education system, which makes distinctions by achieved social position impossible.

Table 1 shows the samples, number of respondents, and response rates. The response rates were quite similar in each survey but during the whole study girls answered more frequently than the boys.

Social class of origin was based on the respondents' report on the occupation of father or the head of the household. If the head of the household was not presently working (mostly the unemployed persons and the pensioners, $5.4 \%$ of the cases) former occupation was used. Occupations were originally classified into five groups according to the status 
Table 2 Construction of categories of social mobility and number of respondents in each category

\begin{tabular}{lllll}
\hline & \multicolumn{2}{c}{ Achieved social position } & & \\
\cline { 2 - 5 } Social class of origin & $\begin{array}{l}\text { Upper secondary school with } \\
\text { good achievement }\end{array}$ & $\begin{array}{l}\text { Upper secondary school with } \\
\text { poor or average achievement; } \\
\text { vocational institutes }\end{array}$ & Vocational schools & School leaver \\
\hline $\begin{array}{llll}\text { Upper white collar } \\
\text { Lower white collar }\end{array}$ & $\begin{array}{l}\text { Stable }(\mathrm{n}=664) \\
\text { Upwardly mobile }(\mathrm{n}=604)\end{array}$ & $\begin{array}{l}\star \mathrm{n}=532) \\
\text { Stable }(\mathrm{n}=743)\end{array}$ & $\begin{array}{l}\text { Downwardly mobile }(\mathrm{n}=184) \\
\text { Downwardly mobile } \\
(\mathrm{n}=588)\end{array}$ & $\begin{array}{l}\text { Down } \\
(\mathrm{n}=313)\end{array}$ \\
\hline
\end{tabular}

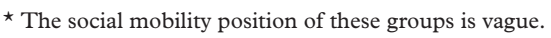

classification of the Central Statistics Office of Finland (upper and lower white collar workers, skilled and unskilled blue collar workers and farmers).$^{22}$ The two groups of blue collar workers were combined as the number of unskilled workers was too small for purposes of analysis. Additionally, in the tables the blue collar workers and farmers, both representing lower socioeconomic groups in Finland, were combined to get larger numbers. In separate analyses (not presented) the main findings were similar for both groups.

Achieved social position was measured by the present educational status, school attainment, and labour market position. In the Finnish educational system of the $1980 \mathrm{~s}$, one crucial point in the occupational and educational career took place at the age of 16 . Basically there were three tracks: to continue in upper secondary or vocational education or to leave school. Vocational schools most often aimed at blue collar occupations and vocational institutes usually at lower white collar occupations (combined $33 \%$ of our respondents). Most of the young people that continued in full time education applied to upper secondary schools ( $50 \%$ of the respondents), which after a matriculation examination give theoretic eligibility to continue in academic studies. These paths did not, of course, determine wholly the occupational careers of individuals later in life but they do present the overall educational segregation patterns.

As most young people continue to upper secondary schools, school attainment becomes crucial in influencing further educational career. Good marks suggest a better chance to continue into higher education. Here, the respondents were asked to assess their latest school marks and to compare them with the average of their class. School achievement was classified into good $(43 \%$ of those still studying) and average or poor (57\%).

Labour market position was the third criterion of the achieved social position of young people. Based on this criterion, school leavers $(17 \%$ of the respondents) were separated from those who attended full time education. The present occupation of the young people was not asked in the surveys as only slightly more than $10 \%$ of these age groups are employed and most of them in low status occupations. In addition to the employed young people, school leavers comprise of unemployed, those (males) who are in military service and those that stay at home.

Based on these criteria the achieved social position was divided into the four categories presented in table 2 . The direction of social mobility (upwardly mobile, stable, and downwardly mobile) was defined as a combination of the social class of origin and the achieved social position. Its definitions, constructed separately for each social class of origin are presented in table 2 .

For some of the combinations it was quite problematic to define the direction of mobility so these were excluded from the analyses concerning relative risks (altogether 31\% respondents). Leaving the ambivalent categories out strengthened contrasts and illustrates better the effects of social mobility. The relative risks are presented only for those whose direction of mobility could be clearly defined (tables 5 to 8 ).

The other analyses, including the logistic regression analyses, covered all respondents. In the logistic regression models, the independent effects of the social class of origin and the achieved social position were analysed thus allowing for all respondents also to be taken into the final phase of the study.

Missing data concerning the variable measuring social mobility were found for 195 respondents $(2 \%)$. This was mainly caused by missing data from the educational attainment and occupation of the head of the household.

Nine measures of health related behaviour were chosen. Use of tobacco was ascertained through several questions and daily smoking was analysed. Daily smokers $(31 \%$ of respondents) had smoked at least 50 cigarettes, cigars or pipes during their lifetime and reported smoking daily or reported smoking more than one cigarette a day, although they may have assessed their smoking frequency "once a week or more often, not daily". Using these criteria those who considered themselves ex-smokers but had smoked within the previous week were also defined as daily smokers. In other words, should a discrepancy between answers occur, priority was given to the respondent's report of the daily amount of cigarettes (cigars or pipes), instead of the broader assessment of the smoking frequency. In an earlier cohort these cases numbered $3.7 \%$ of the whole category of daily smokers and they arise from the fact that at this age smoking patterns have not, yet, become fully established. ${ }^{23}$

There were two questions on alcohol use. A single structured question measured the overall frequency of drinking: "How often do you use alcohol? Also try to remember the situations in which you have used only small amounts, such as half a bottle of medium beer or a sip of wine." Nine alternatives were given, ranging from "daily" to "I do not use alcohol". Weekly 
Table 3 Health related behaviours by the social class of origin. Proportion (\%) of the adolescents having adopted the behaviour

\begin{tabular}{llll}
\hline & \multicolumn{2}{l}{ Social class of origin } & \\
\cline { 2 - 4 } Health related behaviour & $\begin{array}{l}\text { Upper white collar } \\
(n=1389)\end{array}$ & $\begin{array}{l}\text { Lower white collar } \\
(n=2271)\end{array}$ & $\begin{array}{l}\text { Blue collar workers and farmers } \\
(n=4517)\end{array}$ \\
\hline Daily smoking & 26 & 33 & 32 \\
Weekly use of alcohol & 23 & 22 & 19 \\
Heavily intoxicated > once a month & 20 & 23 & 20 \\
More than 3 cups of coffee daily & 11 & 19 & 27 \\
No physical exercise & 7 & 8 & 8 \\
Does not brush teeth daily & 9 & 13 & 19 \\
Butter as a bread spread & 27 & 30 & 43 \\
High fat milk usually & 6 & 13 & 28 \\
Sweets daily & 26 & 26 & 23 \\
\hline
\end{tabular}

use of alcohol (20\% of respondents) was analysed as an indicator of frequent alcohol use. The second question was about heavy alcohol use: "How often do you drink so that you end up being heavily intoxicated?" Those that reported heavy intoxication at least once a month $(21 \%)$ were regarded as heavy drinkers. Other measures were based on one structured question each. The measures were: drinking three cups of coffee or more daily $(23 \%)$, not brushing teeth daily (16\%), using sweets daily (24\%), usually selecting butter as a bread spread $(37 \%)$, and usually drinking high fat milk (20\%). The last two were used as measures of a diet high on milk fat. The measure of physical activity was also based on a single question: "Which of the following describes best your physical activity? I engage in sports or physical activity generally so, that". The respondents that chose the option "I do not engage in physical activity at all during my leisure time" were considered as taking no physical exercise ( $8 \%)$. Missing data concerning health related behaviour ranged from 0.0 to $1.3 \%$.

The reliability of the health related behaviour measures was assessed in a one month repetition that was sent a subsample $(n=403)$ of the 16 year olds. $^{24}$ The $\kappa$ test of reliability was calculated to measure the consistency-testretest agreement beyond chance- - between two measurements of the same variable. With the exception of physical activity, which had only a fair $(0.48)$ weighted $\kappa$ value, all measures had values that ranged from good to excellent reliability according to the criteria given by Fleiss. ${ }^{25}$ The fair reliability of the physical activity measure probably reflects the true inconsistency of the activity patterns of young people. Still, the lower reliability of the measure has to taken into account when assessing the results.
Firstly, the relation between both measures of social status and the health related behaviour measures was studied by cross tabulating them and by testing the significance of the relation with the $\chi^{2}$ test. Secondly, the outcome of social mobility on health related behaviour was measured by comparing the adoption of each behaviour in an upwardly or downwardly mobile group with a stable group from the same social class of origin. Relative risks were assessed by calculating age and sex adjusted rate ratios approximating a Mantel-Haenszel estimate. ${ }^{26}$ Ninety five per cent test based confidence limits were calculated. ${ }^{27}$ The relative risk for a stable group was denoted by 1.0. Thus, if the relative risk in the mobile group was higher than 1.0, the risk of adopting the behaviour was higher than in the stable group, and if it was lower, the risk was lower.

Logistic regression analyses were made using the GLIM program. ${ }^{28}$ They were performed to assess the independent effects of the social class of origin and the achieved social position as well as their interaction on the risk of adopting each of the nine behaviours. Models were fitted stepwise so that the significance of age and sex were first tested. Next, the social class of origin and the achieved social position were introduced in order of their statistical significance. Finally, we tested whether adding the interaction term of the two social class variables improved statistically significantly the fit of the model. An interaction was interpreted to measure the movement effect, that is, the influence of the change from one position to another after the main effects of the social class of origin and the achieved social position were taken into account. The significance of adding a variable and their interactions to the models were tested with the Pearson's $\chi^{2}$ test $(\mathrm{p}<0.05)$. A statistically significant contribution to the

Table 4 Health related behaviours by achieved social position. Proportion (\%) of adolescents having adopted the behaviour in each group

\begin{tabular}{|c|c|c|c|c|}
\hline \multirow[b]{2}{*}{ Behaviour } & \multicolumn{4}{|l|}{ Achieved social position } \\
\hline & $\begin{array}{l}\text { Upper secondary school } \\
\text { with good attainment } \\
(n=2117)\end{array}$ & $\begin{array}{l}\text { Upper secondary school with poor or } \\
\text { average attainment; vocational institute } \\
(n=2388)\end{array}$ & $\begin{array}{l}\text { Vocational } \\
\text { school } \\
(n=1797)\end{array}$ & $\begin{array}{l}\text { School } \\
\text { leaver } \\
(n=1428)\end{array}$ \\
\hline Daily smoking & 12 & 26 & 40 & 53 \\
\hline Weekly use of alcohol & 14 & 19 & 22 & 33 \\
\hline Heavily intoxicated $>$ once a month & 11 & 21 & 26 & 30 \\
\hline More than 3 cups of coffee daily & 11 & 16 & 28 & 41 \\
\hline No physical exercise & 4 & 6 & 8 & 16 \\
\hline Does not brush teeth daily & 6 & 9 & 25 & 27 \\
\hline Butter as a bread spread & 33 & 35 & 41 & 38 \\
\hline High fat milk usually & 13 & 15 & 27 & 29 \\
\hline Sweets daily & 21 & 27 & 25 & 23 \\
\hline
\end{tabular}


Table 5 Relative risk of adopting health related behaviours and its $95 \%$ confidence intervals (CI), for the downwardly mobile children of upper white collar workers. Risk for the stable children of the same origin=1.0. Age and sex adjusted

\begin{tabular}{lll}
\hline Behaviour & Relative risk & $95 \%$ CI \\
\hline Daily smoking & 4.0 & $3.1,5.2$ \\
Weekly use of alcohol & 1.9 & $1.4,2.4$ \\
Heavily intoxicated more than once a month & 2.2 & $1.7,3.0$ \\
More than 3 cups of coffee daily & 3.3 & $2.2,4.8$ \\
No physical exercise & 3.6 & $2.0,6.4$ \\
Does not brush teeth daily & 3.1 & $2.0,4.8$ \\
Butter as a bread spread & 1.1 & $0.8,1.4$ \\
High fat milk usually & 2.4 & $1.4,4.1$ \\
Sweets daily & 1.0 & $0.7,1.4$ \\
\hline
\end{tabular}

Table 6 Relative risk of adopting health related behaviours and its 95\% confidence intervals (CI), for downwardly mobile children of lower white collar workers. Risk for stable children of the same origin=1.0. Age and sex adjusted

\begin{tabular}{lll}
\hline Behaviour & Relative risk & $95 \%$ CI \\
\hline Daily smoking & 2.0 & $1.7,2.4$ \\
Weekly use of alcohol & 1.4 & $1.2,1.8$ \\
Heavily intoxicated more than once a month & 1.4 & $1.2,1.8$ \\
More than 3 cups of coffee daily & 2.4 & $1.9,3.0$ \\
No physical exercise & 3.7 & $2.5,5.4$ \\
Does not brush teeth daily & 2.3 & $1.6,3.2$ \\
Butter as a bread spread & 0.9 & $0.7,1.1$ \\
High fat milk usually & 1.9 & $1.4,2.7$ \\
Sweets daily & 0.9 & $0.7,1.2$ \\
\hline
\end{tabular}

Table 7 Relative risk of adopting health related behaviours and its 95\% confidence intervals (CI), for upwardly mobile children of blue collar workers and farmers. Risk for stable children of the same origin=1.0. Age and sex adjusted

\begin{tabular}{lll}
\hline Behaviour & Relative risk & $95 \% C I$ \\
\hline Daily smoking & 0.2 & $0.2,0.3$ \\
Weekly use of alcohol & 0.5 & $0.4,0.6$ \\
Heavily intoxicated more than once a month & 0.5 & $0.4,0.6$ \\
More than 3 cups of coffee daily & 0.5 & $0.4,0.5$ \\
No physical exercise & 0.3 & $0.2,0.4$ \\
Does not brush teeth daily & 0.3 & $0.2,0.4$ \\
Butter as a bread spread & 1.1 & $1.0,1.2$ \\
High fat milk usually & 0.8 & $0.7,1.0$ \\
Sweets daily & 0.8 & $0.6,0.9$ \\
\hline
\end{tabular}

Table 8 Relative risk of adopting health related behaviours and its 95\% confidence intervals (CI), for upwardly mobile children of lower white collar workers. Risk for stable children of the same origin=1.0. Age and sex adjusted

\begin{tabular}{lll}
\hline Behaviour & Relative risk & $95 \%$ CI \\
\hline Daily smoking & 0.4 & $0.4,0.6$ \\
Weekly use of alcohol & 0.6 & $0.5,0.7$ \\
Heavily intoxicated more than once a month & 0.4 & $0.3,0.5$ \\
More than 3 cups of coffee daily & 0.7 & $0.3,1.5$ \\
No physical exercise & 0.8 & $0.5,1.3$ \\
Does not brush teeth daily & 0.6 & $0.4,0.9$ \\
Butter as a bread spread & 0.9 & $0.8,1.1$ \\
High fat milk usually & 1.0 & $0.7,1.4$ \\
Sweets daily & 0.7 & $0.6,0.9$ \\
\hline
\end{tabular}

particular estimates of health related behaviours is interpreted to represent the movement effect. For example, should the interaction model predict a statistically significant increase in smoking among a downwardly mobile group compared with the main effects model, this would be considered as a movement effect.

\section{Results}

The relations between the two social class measures and health related behaviour are presented in tables 3 (for social class of origin) and 4 (achieved social position). With the exception of lack of physical exercise, of alcohol use, and of sweets use, the adoption of health related behaviours was moderately, but systematically related to the social class of origin (table 3). The largest differences between social classes
KEY POINTS

- Upward mobility improves health promoting behaviours and downward mobility health compromising behaviours among young people.

- Health related behaviours are best promoted through education as the mobile young people tend to behave according to their educational group.

- That social mobility associated with health related behaviours may partly explain the social class differences in health observed among adults.

were observed in the use of high fat milk products. The achieved social position was more strongly related to the behaviours than the social class of origin (table 4). Only the use of butter as a bread spread and the use of sweets daily did not vary systematically by the achieved social position. Still, even these behaviours differed significantly between different achieved social positional groups.

In table 5, the relative risks of adopting the health related behaviours for downwardly mobile children of upper white collar workers are compared with the stable group of the same origin. A similar comparison between the downwardly mobile and the stable group is made among children of lower white collar workers in table 6 . The risks of adopting any of the nine health compromising behaviours, except for using butter as a bread spread and sweets daily, were significantly higher for the downwardly mobile than stable children. The risks were somewhat higher among those who came from the upper while collar families, than among those who came from the lower white collar families.

The upwardly mobile children of farmers and blue collar workers had a significantly lower risk of adopting any of the health related behaviours, except for using butter as a bread spread and sweets daily, than the stable children from the same social class of origin (table 7). The upwardly mobile children of the lower white collar workers differed in the same way, but less strikingly from the stable group of the same origin (table 8). In this group the risks were lower for the upwardly mobile than the stable children in all behaviours, except for use of high fat milk. Five of the behaviour measures showed significantly lower risks.

The best fit logistic regression models that were made to test the independent (main) effects of the social class of origin and the achieved social position on the adoption of each of the health related behaviours are summarised in table 9. After adjusting for significant age and sex effects, the achieved social position was more strongly related to the health related behaviour than the social class of origin in most behaviours. For example, among the school leavers, the odds ratio for not brushing teeth was highest, 5.63 (95\% CI 4.37, 7.26), whereas those coming from blue collar worker and farmer families, which was the origin group with the highest likelihood of not brushing 
Table 9 Best fit logistic models for the health related behaviours, their scaled deviance (sd) and degrees of freedom $(d f)$

\begin{tabular}{llcc}
\hline Behaviour & Model $^{\star}$ & $s d$ & $d f$ \\
\hline Daily smoking & sex+age+achv+orig & 37.8 & 40 \\
Weekly use of alcohol & sex+age+achv+orig & 59.8 & 40 \\
Heavily intoxicated more than once a month & sex+age+achv+orig+origtachv & 64.6 & 34 \\
More than 3 cups of coffee daily & sex+age+achv+orig & 47.3 & 40 \\
No physical exercise & sex+age+achv & 43.7 & 42 \\
Does not brush teeth daily & sex+age+achv+orig & 50.1 & 40 \\
Butter as a bread spread & sex+orig & 41.6 & 44 \\
High fat milk usually & sex+orig+achv+orig†achv & 54.4 & 35 \\
Sweets daily & age+achv+orig & 44.3 & 41 \\
\hline
\end{tabular}

$\star$ Orig $=$ social class of origin, achv $=$ achieved social position, orig $\nmid a c h v=$ an interaction between social class of origin and achieved social position.

teeth, had only a moderately increased odds ratio of $1.62(1.28,2.05)$. Similarly, the odds for frequent coffee drinking was high among school leavers $(4.23,95 \%$ CI $3.50,5.11)$ but less increased among blue collar worker's or farmer's children $(2.14 ; 1.74,2.62)$. In the latter group smoking $(0.65 ; 0.55,0.76)$, alcohol use $(0.52 ; 0.44,0.62)$ and sweets use $(0.82 ; 0.70$, $0.95)$ were lowered, but the effect was smaller than the increase according to the achieved social position. School leavers had an odds of $9.36(7.78,11.27)$ for smoking, of 2.23 (1.84, 2.70) for alcohol use and of $1.29(1.08,1.54)$ for sweets use.

In the models of the use of high fat milk products (butter or high fat milk) the relative impact of these variables was reversed. After the social class of origin was adjusted in the model for butter use, the achieved position was no longer statistically significant. The model for high fat milk suggested a stronger effect for the social class of origin than the achieved social position. According to the main effects model children from farmer and blue collar families had an odds of $5.20(4.06,6.66)$ for high fat milk use, when among school leavers the odds was only $1.73(1.44,2.09)$.

The interaction between the social class of origin and the achieved position improved the fit of the model in two cases: heavy intoxication more often than once a month $(\mathrm{p}=0.03)$ and use of high fat milk $(p=0.03)$ (table 9). Generally, these interactions produced only small, although significant, effects onto the relation between the behaviours and their socioeconomic covariants (data not shown). Still, in both models a considerable interaction effect was found: in the first case, heavy intoxication was, according to the interaction model, clearly lower among the upwardly mobile children of the lower white collar families than according to the main effects model (odds for frequent heavy intoxication 0.61 and 0.87 , respectively). In the latter case, the interaction model predicted higher odds for high fat milk use for the downwardly mobile children of the upper white collar families than did the main effects model (odds 3.01 and 1.57 respectively).

\section{Discussion}

The main finding of our study was the clear and consistent relation between health related behaviour and social mobility. Most of the nine behaviours studied were related to the direction of mobility so that health related behaviour was more frequent among downwardly mobile young people and less frequent among upwardly mobile young people than their stable age mates.

Instead, the movement effect-that is, whether young people actually were moving up or down-did not seem to be related to health related behaviour. According to the multivariate analyses only frequent heavy intoxication and high fat milk use were influenced by the movement effect. For example, those young people that fell into a low status position from a high social class of origin had an increased risk of drinking high fat milk than would statistically have been expected of young people with their background and current position.

That the findings in this respect were somewhat unexpected may, however, have partly resulted from the age group studied. At the age of 16 to 18 the achieved social position, which was here measured on the basis of the level and type of education, does not necessarily fully predict the social class in adulthood. Although education in Finnish society is considered to be the main selective mechanism through which occupational social position and social class are achieved and although our measure is likely to correlate strongly with the adult social class position, measuring social mobility among young people may have introduced some bias. 202930

However, should bias of this type be present, it is more likely to obscure the differences between mobility groups than to have produced artificial results. Social desirability has been suggested to relate to respondence, for example, so that the respondents tend to have more desirable patterns of health related behaviour than the non-respondents. ${ }^{23}$ Thus, it may well be that non-respondents are to some degree also selected according to social mobility. According to the social desirability hypothesis, then, it seems reasonable to expect that the downwardly mobile group would be especially prevalent among non-respondents. If this is correct, then the relation between health related behaviour and social mobility is probably even stronger than the one that we have been able to demonstrate here.

The strength of mobility was found by Burrows and Nettleton ${ }^{19}$ to be related to smoking and drinking among the middle classes in Britain. Men, but significantly not women, from manual backgrounds who had been socially most mobile upward were least likely to engage in these health related behaviours. Burrows and Nettleton interpret this to show an eagerness of these men to distance culturally themselves from their social class of origin. Our findings concerning the movement effect corroborates with their notion in suggesting that those young people from particular social groups that were moving down were more likely and those moving up less likely to adopt frequent drunkenness and high fat milk use because of experiencing social mobility.

As the study is cross sectional the causal direction of the relation between social mobility and the adoption of health related behaviour cannot be determined. Basically, the relation may have developed in two ways: either socially 
mobile young people adopt the behaviours prevalent in the group, where they are likely to end up, or mobility itself results from their health related behaviour.

The former notion is supported by Burrows and Nettleton. ${ }^{19}$ They suggest that those who move into the middle class will tend to take on its dominant cultural characteristics. Our findings suggest that in addition to drinking and smoking, at least among young people, a similar process may also take place in diet, physical activity, and oral health behaviour. In this way, working class people would "choose" the health compromising working class lifestyle and the middle classes their own more health promoting behaviour. ${ }^{31}$

However, particularly as we have focused on young people, the latter explanation that points to indirect consequences of social mobility may lie behind these findings. Among this age group engaging early in health compromising behaviour - or la Dolce Vita, as it has been labelled by Hallman et $a \beta^{2}$-may influence school performance and, later, the educational career so that those, who already have adopted health compromising behaviours, end up in lower social classes and vice versa.

Whatever the precise mechanism that creates this relation, our findings emphasise the role of education in this process, as it is education through which young people of this age are selected into different social classes. At the same time education facilitates a number of influences that are related to the adoption of health related behaviour, such as health related knowledge, attitudes, and orientations.

At younger ages, particularly, health related behaviour is likely to be influenced by home environment, as most of the young people at the age of 16 to 18 still live at their parents' home. Young people's behaviour may depend on the extent to which their parents allow or control for particular behaviour patterns. In our study dietary behaviour, especially butter use, was strongly related to the social class of origin. At this age young people apparently still adapt to the dietary choices of their family, like, for example, the frequent use of butter in farmer and blue collar families. Julia Brannen et $a b^{33}$ found, however, that among the 16 year olds food is likely to develop an area where young people (re)negotiate their more independent role to achieve an adult status in the family. However, the independent grown up status is fully established only when the young people leave home, which in Finland often takes place quite early. It may naturally, particularly among school leavers, happen already at 16 , which would reduce the home influence even further.

However, among young people direct health differences by social class-when measured by social class of origin - are relatively small. ${ }^{16} 2934$ Thus, we can conclude that indirect influences are more probable. Particularly based on this study it seems that health related behaviour that is related to social mobility may partly contribute to social class differences in the long run. The health related effects of these behaviours are mainly not yet apparent but they are likely to manifest themselves later thus producing inequalities between social classes in adulthood.

Funding: the Ministry of Social Affairs and Health, Finland and the Eidgenössische Stipendienkommission für Ausländische Studierende, Switzerland have supported the study.

Conflicts of interest: none.

1 Illsley R. Social class selection and class differences in relation to stillbirths and infant deaths. BMF 1955;2:1520.

2 Townsend P, Davidson N. Inequalities in health: the Black Report. Suffolk: Penguin Books, 1982.

3 Wilkinson RG, ed. Class and health. Research and longitudinal data. London: Tavistock Publications, 1986.

4 Fogelman K, Fox AJ, Power C. Class and tenure mobility: do they explain social inequalities in health among young adults in Britain? In: Fox J, ed. Health inequalities in European countries. Southampton: Gower, 1989:280-300.

5 Wilkinson RG. Socio-economic differences in mortality: interpreteting the data on their size and trends. In: Wilkinson RG, ed Class and health. Research and longitudinal data. son RG, ed. Class and health. Research and longitudinal date. London: Tavistock Publications, 1986:1-20.

West P. Rethinking the health selection explanation for health inequalities. Soc Sci Med 1991;32:373.

7 Lundberg O. Childhood living conditions, health status, and ocial mobility: a contribution to the health selection debate. European Sociological Reviezw 1991;7:149-62.

8 Blane D, Davey Smith G, Bartley M. Social selection: what does it contribute to social class differences in health? Sociology of Health and Illness 1993;15:1-15.

9 Power C, Fogelman K, Fox J. Health and social mobility during the early years of life. Quarterly fournal of Social Affairs 1986;2:397-413.

10 Nyström Peck AM. Childhood environment, intergenerational mobility, and adult health - evidence from Swedish data. F Epidemiol Community Health 1992;46:71-4.

11 Cernerud L. Height and social mobility. Scand $\mathcal{F}$ Soc Med 1995;23:28-31.

12 Asford S. Upward mobility, status inconsistency and psychological health. F Soc Psychol 1990;130:71-6.

13 Sweeting H, West P. Family life and health in adolescence: a role for culture in the health inequalities debate? Soc Sci Med $1995 ; 40: 163-75$.

14 Power C, Manor O, Fox J, et al. Health in childhood and social inequalities in health in young adults. fournal of Royal social inequalities in health in youn

15 Power C, Manor O, Fox J. Health and class: the early years. London: Chapman and Hall, 1991.

16 West P. Health inequalities in the early years: is there equalisation in youth. Soc Sci Med 1997; 44:833-58.

17 Lynch JW, Kaplan GA, Salonen JT. Why do poor people behave poorly? Variation in adult health behaviours and psychosocial characteristics by stages of the socioeconomic lifecourse. Soc Sci Med 1997;44:809-19.

18 Koivusilta L, Rimpelä A, Rimpelä M. Health-related lifestyle in adolescence predicts adult educational level: a longitudinal study from Finland. F Epidemiol Community Health 1998; 52:794-801.

19 Burrows R, Nettleton S. Going against the grain: smoking and 'heavy' drinking amongst the British middle classes. Sociology of Health and Illness 1995;17:668-80.

20 Glendinning A, Shucksmith J, Hendry L. Social class and adolescent smoking behaviour. Soc Sci Med 1994;38: adolescen

21 Rimpelä M, Rimpelä A, Rahkonen O, et al. The evolution of the Juvenile Health Habit Study 1977-1985. In: Anderson R, Davies JK, Kickbush I, et al, eds. Health behaviour research and health promotion. Oxford: Oxford University Press, 1988

22 Central Statistics Office of Finland. Classification of occupations. Helsinki: Central Statistics Office, 1975.

23 Ahlström S, Eskola A, Honkala E, et al. Nuorten terveystapatutkimus. Tutkimusohjelman lähtökohdat ja toteutus. Tampere: Kansanterveystieteen julkaisuja, 1979:M48.

24 Karvonen S. The regional context of health behaviour among young people. Research reports 76 . Jyväskylä: Stakes, 1997.

5 Fleiss JL. Statistical methods for rates and proportions. New York: John Wiley, 1981.

26 Mantel N, Haenszel W. Statistical aspects of the analysis of data from retrospective studies of disease. $\mathcal{F}$ Natl Cancer Inst 1959;22:719-48.

27 Miettinen OS. Theoretical epidemiology. Principles of occurrence research in medicine. New York: Wiley, 1985.

28 Aitkin M, Anderson D, Francis B, et al. Statistical modelling in GLIM. Guildford: Oxford Science Publications, 1990.

29 Rahkonen O. Adolescence to adulthood - the re-emergence of social class differences in health? Working papers no. 13. Helsinki: University of Helsinki, Department of Sociology, 1992.

30 Silvennoinen $H$. Nuorten kouluttamattomuuden ja työtömyyden rakenteelliset yhteydet. Nuorisotutkimus 1993;11: $3-17$

31 Willis P. Learning to labour: how working class kids get working class jobs. Westmead: Saxon House, 1979.

32 Hallman M, Kannas L, Tynjälä J. Tupakka, tuoppi ja elämisen terveystyyli. Raportteja 61. Helsinki: Sosiaali- ja Terveyshallitus, 1992 .

33 Brannen J, Dodd K, Oakley A, et al. Young people, health and family life. Buckingham: Open University Press, 1994.

34 Macintyre S, West P. Lack of class variation in health in adolescence: an artefact of an occupational measure of social class. Soc Sci Med 1991;32:395-402. 